Pediatric Optic Neuritis. Curr Neurol Neurosci Rep, 20(3), 4.

2. Lehman S.S. and Lavrich J.B. (2018). Pediatric optic neuritis. Curr Opin Ophthalmol, 29(5), 419422.

3. Wilejto M., Shroff M., Buncic J.R., et al. (2006). The clinical features, MRI findings, and outcome of optic neuritis in children. Neurology, 67(2), 258-262.

4. Averseng-Peaureaux D., Mizzi M., Colineaux $H_{.}$, et al. (2018). Paediatric optic neuritis: factors leading to unfavourable outcome and relapses. $\mathrm{Br}$ J Ophthalmol, 102(6), 808-813.

5. Lê Thi Doan (2013). Nghiên cứu một số đặc điểm lấm sàng và kết quả điều trị bênh viêm thị thần kinh ở trẻ em tại Bệnh viện Mắt trung ương trong 5 năm (2008-2012).
6. Ambika S., Padmalakshmi K., Venkatraman V., et al. (2018). Visual Outcomes and Clinical Manifestations of Pediatric Optic Neuritis in Indian Population: An Institutional Study. J NeuroOphthalmol Off J North Am Neuro-Ophthalmol Soc, 38(4), 462-465.

7. Absoud M., Cummins C., Desai N., et al. (2011). Childhood optic neuritis clinical features and outcome. Arch Dis Child, 96(9), 860-862.

8. Sri-udomkajorn S. and Pongwatcharaporn K. (2011). Clinical features and outcome of childhood optic neuritis at Queen Sirikit National Institute of Child Health. J Med Assoc Thail Chotmaihet Thangphaet, 94 Suppl 3, S189-194.

9. Yeh E.A., Graves J.S., Benson L.A., et al. (2016). Pediatric optic neuritis. Neurology, 87(9 Suppl 2), S53-58.

\title{
KẾT QUẢ ĐIỀU TRI UNG THƯ TRỰC TRÀNG THÁP (T3-4) ĐƯỢC ĐÎ̀U TRI HÓA XẠ TRI BỔ TRỢ TRƯỚC VÀ PHẪU THUÂTT BẢO TỒN CƠ THẤT
}

Đỗ Tất Cường ${ }^{1}$, Bùi Vinh Quang ${ }^{1}$, Hoàng Mạnh Thắng², Nịnh Thị Thảo ${ }^{1}$, Nguyễn Hoàng Gia ${ }^{1}$, Võ Quốc Hoàn ${ }^{1}$, Trần Quang Kiên ${ }^{1}$, Nguyễn Hoài Nam ${ }^{1}$, Phạm Anh Đức ${ }^{1}$

\section{TÓM TẮT}

Mục tiêu: Đánh giá kết quả điều trị ung thư trực tràng thấp (T3-4) được hóa xạ trị bổ trợ trước và phẩu thuật bảo tồn cơ thắt. Đối tượng và phương pháp nghiên cứu: Nghiên cứu mô tả cắt ngang trên 44 bệnh nhân ung thư trực tràng giai đoạn T3-4N0-2MO tại Bệnh viện $K$ và Bệnh viện Ung Bướu Hà Nội từ năm 5/2016 đến 5/2021 được hóa xa tri tiền phầu sau đó phẫu thuật bảo tồn cơ thắt. Kết quả: Sau điều trị hóa xa trì, tỷ lê đáp ứng hoàn toàn, đáp ứng một phần, bệnh ôn định lần lượt là $9,1 \%, 52,3 \%$ và $38,6 \%$. Không ghi nhân trường hợp nào bênh tiến triển. Thời gian sổng thêm không bệnh (DFS) trung bình là 45,16 33,51 tháng. Tỷ lê sống thêm không bệnh 1 năm là $97 \%$, tại thời điểm 2 năm là $77,4 \%$, tại thờ điểm 3 năm là $68,3 \%$.Kết luân: Hóa xạ trị bổ trợ trước và phẫu thuâat bảo tồn cơ thắt là phương án điều trị hiệu quả ở nhóm bệnh nhân UTTT thấp giai đoạn tiến triển tai chố.

Tư khóa: Hóa xa trước phẫu thuật, bảo tồn cơ thắt, giai đoạn tiến triển tại chỗ, ung thư trực tràng thấp.

\section{SUMMARY \\ EFFECTIVENESS OF PREOPERATIVE CHEMORADIOTHERAPY AND SPHINCTER PRESERVING SURGERY FOR RECTAL}

\footnotetext{
${ }^{1}$ Bệnh viện Ung Bướu Hà Nội

${ }^{2}$ Bênh viên $K$

Chịu trách nhiệm chính: Đỗ Tất Cường

Email: tatcuong0310@gmail.com

Ngày nhận bài: 30.7.2021

Ngày phản biên khoa họ: 29.9.2021

Ngày duyệt bài: 6.10 .2021
}

\section{CANCER (T3-T4)}

Objective: To evaluate the efficiency of preoperative chemoradiotherapy and sphincterpreserving surgery for patients with locally advanced distal rectal cancer. Patients and methods: Description study of 44 patients with locally advanced distal rectal cancer who had received preoperative chemoradiotherapy and sphincter-preserving surgery between May 2016 and May 2021. Results: According the pathologic examination of rescted specimens in patients who had received neo-adjuvant chemoradiotherapy, complete pathologic response was observed in $9,1 \%, 52,3 \%$ showed near complete pathologic response. The mean disease free survival (DFS) was $45,16 \pm 3,51$ months. DFS rates of 1 year, 2 years and 3 years were respectively $97 \%, 77,4 \%$ and $68,3 \%$. Conclusion: Preoperative chemoradiotherapy and sphincter preserving surgery is the cornerstone and effective treatment in locally advanced distal rectal cancer.

Key words: preoperative chemoradiotherapy, anal sphincter preserving surgery, locally advanced, rectal cancer.

\section{I. ĐẶT VẤN ĐỀ}

Ung thư trực tràng (UTTT) là một trong những bệnh ung thư phổ biến ở nước ta và các nước trền thế giới. Theo ước tính của GLOBOCAN 2018, tại Viêt Nam có 8815 trường hợp mắc mới, với tý suất 5,4/100.000, và 4673 trường hợp tử vong do UTT, với tỷ suất 4,1/100.000[1].

Hiện nay, bệnh nhân UTTT đến khám bệnh ở giai đoạn muộn, nên tỷ lệ các bệnh nhân được điều trị phẫu thuật triệt căn và phẫu thuật bảo 
tồn cơ tròn hậu môn thấp. Xu hướng điều trị đối với các bệnh nhân UTTT thấp tiến triển tại chỗ hiện nay chủ yếu là hóa xạ trị tiền phấu sau đó là phẫu thuật cắt toàn bộ trực tràng, ống hậu môn mà không điều trị bảo tồn cơ thắt. Tuy nhiên, việc điều trị này cũng mang lại nhiều bất lợi về chất lượng sống cho bệnh nhân. Đã có nhiều nghiên cứu chỉ ra rằng điều trị kết hợp đồng thời hóa chất với xạ trị trước mổ ở bệnh nhân UTTT giai đoạn tiến triển tại chỗ giúp hạ thấp giai đoạn bệnh, tạo điều kiện thuận lợi cho phẫu thuật và tăng tỉ lệ bảo tồn cơ thắt hậu môn.

Cho tới nay còn ít nghiên cứu trong nước đánh giá về kết quả điều trị đối với các bệnh nhân ung thư trực tràng thấp sau hóa xa tiền phẫu kết hợp phấu thuật bảo tồn cơ thắt. Vì vậy, chúng tôi tiến hành nghiên cứu này với mục tiều: Đánh giá kết quả điều trị ung thư trực tràng thấp (T3-4) được hóa xạ trị bồ trợ trước và phẫu thuật bảo tồn cơ thắt.

\section{II. ĐỐI TƯợNG VÀ PHƯƠNG PHÁP NGHIÊN CỨU}

2.1. Thời gian và địa điểm: Chọn các bệnh nhân được điêu trị từ 5/2016 đến 5/2021 tại Bệnh viện $\mathrm{K}$ và Bệnh viện Ung Bướu Hà Nội.

\section{2. Đối tượng nghiên cứu}

2.2.1. Tiêu chuẩn chọn bệnh nhân nghiên cứu:

- Chẩn đoán ung thư trực tràng thấp:

$+U$ trực tràng cách rìa hậu môn dưới $5 \mathrm{~cm}$

+ Có kết quả chẩn đoán mô bệnh học khẳng

định ung thư biểu mô tuyến của trực tràng

+ Có chỉ định hóa xạ trước mổ: u ở giai đoạn T3, 4

+ Bệnh nhân chưa có di căn xa

- Được điều trị hóa xạ trị đồng thời trước mổ và phẫu thuật bảo tồn cơ thắt

- Hồ sơ lưu trữ đủ thông tin nghiên cứu

\subsubsection{Tiêu chuẩn loại trừ}

- Ung thư trực tràng giai đoạn u T1, T2, ung thư di căn xa

- Mô bệnh học không phải ung thư biểu mô tuyến.

- Bệnh nhân không được phẫu thuật bảo tồn cơ thắt sau hóa xạ trị đồng thời trước mổ.

2.3. Cỡ mẫu: cỡ mẫu được xác định bằng công thức áp dụng cho nghiên cứu ngang mô tả với tỉ lệ hạ thấp giai đoạn bệnh nhờ phương pháp điểu trị hóa xạ trị trước mổ là $0,74[2]$, độ chính xác mong muổn là $0,2,95 \%$ khoảng tin cậy.

2.4. Phương pháp nghiên cứu: mô tả cắt ngang

2.5. Cách thức tiến hành:

- Thu thập hồ sơ bệnh án theo mẫu bệnh án

- Chọn bệnh nhân đủ tiêu chuẩn vào nghiên cứu

- Ghi nhận các triệu chứng lâm sàng và cận lâm sàng trước khi điều trị.

- Đánh giá bệnh nhân sau điều trị.

2.6. Phân tích số liệu: số liệu được nhập và phân tích sử dụng phần mềm SPSS 21.0. Các chỉ tiêu nghiên cứu bao gồm:

- Tỷ lệ đáp ứng trên mô bệnh học

- Thời gian sống thêm không bệnh (DFS)

2.7. Đạo đức nghiên cứu

- Phương pháp điều trị đã được áp dụng ở nhiều nước trên thế giới.

- Có sự cho phép của bệnh viện.

- Có sự đồng ý hợp tác của bệnh nhân.

\section{KẾT QUẢ NGHIÊN CỨU}

3.1 Đặc điểm đối tượng nghiên cứu. Tuổi trung bình của nhóm bệnh nhân là $56,1 \pm 13,3$ tuổi, đa số các bệnh nhân trên 40 tuổi, chiếm tỉ lệ $81,8 \%$.

Bảng 1: Các triệu chứng lâm sàng

\begin{tabular}{|c|c|c|}
\hline Triệu chứng lâm sàng & $\begin{array}{c}\text { Tân } \\
\text { suất }\end{array}$ & $\begin{array}{c}\text { Tỷ lệ } \\
\%\end{array}$ \\
\hline Đại tiện nhâyy máu & 28 & 63,6 \\
\hline Đau tức hậu môn/ hạ vị & 2 & 4,5 \\
\hline Táo bón/ khó đi ngoài & 4 & 9,1 \\
\hline Mót rặn & 7 & 15,9 \\
\hline Thay đối khuôn phân & 3 & 6,8 \\
\hline
\end{tabular}

Nhận xét: Bệnh nhân vào viện chủ yếu vì lý do đi ngoài phân nhầy máu chiếm tỉ lệ $63,6 \%$.

Bảng 2: Đặc điểm trên MRI của ung thư trực tràng thấp

\begin{tabular}{|c|c|c|}
\hline & Số BN & Tỷ lệ \% \\
\hline Xâm lấn tại chô qua MRI & 42 & 95,5 \\
T3 & 2 & 4,5 \\
T4 & & \\
Tổn thương hạch trên MRI & 15 & 34.1 \\
N0 & 21 & 47,7 \\
N1 & 8 & 18,2 \\
\hline N2
\end{tabular}

Nhân xét: Có 42 trường hợp giai đoạn T3 (95,5\%), 2 trường hợp giai đoạn T4 (4,5\%). Có 29 trường hợp có hạch trên MRI chiếm tỉ lệ $65,9 \%$.

3.2. Đánh giá đáp ứng

Bảng 3: Đáp ứng sau điều trị hóa xạ trị

\begin{tabular}{|c|c|c|}
\hline Đáp ứng & Số BN & Tỹ lệ \% \\
\hline Đáp ứng hoàn toàn & 4 & 9,1 \\
\hline Đáp ứng một phần & 23 & 52,3 \\
\hline Bệnh ốn định & 17 & 38,6 \\
\hline Bệnh tiến triến & 0 & 0 \\
\hline Tống & $\mathbf{4 4}$ & $\mathbf{1 0 0}$ \\
\hline
\end{tabular}

Nhận xét: Tỷ lệ đáp ứng toàn bộ sau điều trị cao $(61.4 \%)$ trong đó $9,1 \%$ bệnh nhân đạt đáp ứng hoàn toàn.

Bảng 4: Thời gian sông thêm không bệnh

\begin{tabular}{|c|c|c|}
\hline $\begin{array}{c}\text { Sống } \\
\text { thêm }\end{array}$ & $\begin{array}{c}\text { DFS trung } \\
\text { bình }\end{array}$ & $\begin{array}{c}\text { Tý lệ sống them } \\
\text { không bệnh (\%) }\end{array}$ \\
\hline
\end{tabular}




\begin{tabular}{|c|c|c|c|c|}
\hline không & (tháng) & \multicolumn{3}{|c|}{ bệnh } \\
\cline { 2 - 5 } & $45,16 \pm 3,51$ & $\begin{array}{c}12 \\
\text { tháng }\end{array}$ & $\begin{array}{c}24 \\
\text { tháng }\end{array}$ & $\begin{array}{c}36 \\
\text { tháng }\end{array}$ \\
\cline { 3 - 5 } & & 97 & 77,4 & 68,3 \\
\hline
\end{tabular}

Nhân xét: Thời gian sống thêm không bệnh trung bình là $45,16 \pm 3,51$ tháng. Tỷ lệ sống thêm không bệnh 1 năm là $97 \%$, tại thời điểm 2 năm là $77,4 \%$, tại thời điểm 3 năm là $68,3 \%$.

\section{BÀN LUÂN}

Nghiên cứu của chúng tôi đánh giá kết quả điều trị hóa xạ trị bổ trợ trước và phẫu thuật bảo tồn cớ thắt trên 44 bệnh nhân UTTT thẩp giai đoạn tiến triển tại chố. Tuổi trung bình của bệnh nhẩn là $56,14 \pm 13,25$ tuổi (từ 30 đến 80 tuổi), trong đó chủ yếu là nhóm bệnh nhân trên 40 tuổi. Kết quả này cũng tương đương với độ tuổi của bệnh nhân được báo cáo trong nghiên cứu của tác giả Phạm Cẩm Phương[3], với tuổi trung bình 58,9 $\pm 12,4$ tuổi; tương tự trong nghiên cứu của Phạm Khánh Toàn với tuổi trung bình là 60,6 (từ 25 đến 88)[4].

Các triệu chứng lâm sàng thường gặp tại thời điểm chẩn đoán là đại tiện nhây máu $63,6 \%$, mót răn $15,9 \%$, táo bón/khó đi ngoài chiếm $9,1 \%$. Triêu chứng đi ngoài phân lẫn máu là hay gặp nhất và là một chỉ báo quan trọng giúp các bác sĩ có định hướng chẩn đoán và sàng lọc ung thư trực tràng sớm. Kết quả này phù hợp với các nghiên cứu khác: nghiên cứu của Phạm Khánh Toàn cho thây tỷ lệ đi ngoài phân lẫn máu chiếm $92,6 \%[4]$, là lí do chính cho việc vào viện của bệnh nhân. Nghiên cứu của Phạm Cẩm Phương cho thây $90,9 \%$ số bệnh nhân đến khám và điều trị bệnh UTTT là do đại tiện phân nhầy máu[3].

Xác định mức độ xâm lấn của u là một trong những yếu tố quan trong để quyết định phác đồ điều trị. Chụp cộng hưởng từ tiểu khung là một phương pháp chẩn đoán hình ảnh rất có giá trị trong đánh giá giai đoạn bệnh UTTT. Kết quả nghiên cứu của chúng tôi thấy rằng $\mathrm{u}$ giai đoan T3 có 42 bệnh nhân chiếm tỷ lệ $95,5 \%$, u giai đoạn T4 có 2 bệnh nhân chiếm tỷ lệ 4,5\%. Tỷ lệ hạch di căn trên cộng hưởng từ là $65,9 \%$. MRI đã̉ được chứng minh là có độ chính xác cao trong việc đánh giá giai đoạn T với độ chính xác khoảng $93 \%$ và cũng có độ chính xác cao trong việc đánh giá di căn hạch khoảng 91\%[5]. Tác giả Sun Ys Fau - Li và CS khi nghiên cứu trên 97 BN UTTT được điều trị hóa xạ trị trước mổ và được đánh giá giai đoạn trước và sau điều trị bằng MRI 1,5 Tesla cho thấy sự phù hợp trong chẩn đoán giai đoạn $T$ và mô bệnh học là 73,2\%[6].

Về đáp ứng của khối u sau điêu trị hóa xa trị trên kết quả giải phẫu bệnh: tỷ lệ đáp ứng một phần sau điều trị cao chiếm 52,3\%; tỷ lệ bệnh nhân ổn định là $38,6 \%$. Tỷ lệ bệnh nhân có đáp ứng một phần với phác đồ cũng tương đương các nghiên cứu khác, như nghiên cứu của Võ Văn Xuân cho thấy tỷ lệ đáp ứng một phần là $73,2 \%[7]$. Nghiên cứu của chúng tôi cũng phù hợp với tác giả Kim JC (2005): 98\% bệnh nhân phâuu thuật triệt căn được thực hiện sau hoá xạ trị, $74 \%$ bệnh nhân bảo tồn được cơ thắt hậu môn, $12 \%$ bệnh nhân không có tế bào ung thư sau phẫu thuậtt[8]. Trong nghiên cứu của chúng tôi, $100 \%$ bệnh nhân có đáp ứng bệnh sau điều trị xạ trị và hạ thấp giai đoạn bệnh, $100 \%$ đều được phẫu thuât bảo tồn cơ thắt hâu môn. $100 \%$ diên cắt trên và diên cắt dưới u đều không còn tế bào ung thư, khổng có trường hợp nào đánh giá có xâm lấn trên MRI sau mổ còn tế bào ung thư. Điêu này chứng tỏ vai trò của xa trị đối với UTTT có hiệu quả trong các bênh nhân ung thư trực tràng thấp có đáp ứng sau xạ trị và được phẫu thuật bảo tồn cơ thắt. Vì vậy, việc chỉ định phẫu thuật bảo tồn cơ thắt là hoàn toàn hợp lý cho các trường hợp này. Tác giả Phạm Cẩm Phương cũng cho thấy điều trị hóa xạ trị trước mổ là phương pháp điều trị hiệu quả cho các bệnh nhân UTTT giai đoạn tiến triển tại chỗ, giúp hạ thấp giai đoạn bệnh, tăng tỷ lệ phẫu thuật triệt căn và phẫu thuật bảo tồn cơ thắt hậu môn[3].

Thời gian sống thêm không bênh trung bình trong nghiên cứu của chúng tôi là $45,16 \pm$ 3,51tháng. Tỷ lệ sống thêm không bệnh tại thời điểm 1 năm, 2 năm, 3 năm lần lượt là: $97 \%$, $77,4 \%$ và $68,3 \%$. Kết quả của chúng tôi cũng tương tự các tác giả trong và ngoài nước khi đánh giá thời gian sống thêm không bênnh ở nhóm bệnh nhân được phẫu thuật bảo tồn cơ thắt. Theo Chamlou R nghiên cứu 90 bệnh nhân UTTT thấp phẫu thuật bảo tồn cơ thắt, thời gian theo dõi 56,2 tháng, ước lượng sống không bệnh dự đoán 5 năm là $75 \%[9]$.

\section{KẾT LUẦN}

Hóa xạ trị tiền phẫu và phẫu thuật bảo tồn cơ thắt là điều trị hiệu quả trong UTTT thấp giai đoạn tiến triển tại chỗ. Cụ thể là:

- Sau hóa xạ trị tiền phẫu, u và hạch đều giảm giai đoạn khi đánh giá bằng MRI, tạo điều kiện thuận lợi để phẫu thuật bảo tồn cơ thắt.

- Tỳ lệ đáp ứng toàn bộ sau điều trị cao $(61,4 \%)$, trong đó $9,1 \%$ bệnh nhân đáp ứng hoàn toàn.

- Thời gian sống thêm không bệnh (DFS) trung bình là $45,16 \pm 3,51$ tháng. 


\section{TÀI LIÊU THAM KHẢO}

1. Globocan. Colorectal cancer incidence and mortality worldwide in 2018. International agency for research on cancer. 2018

2. Elwanis MA, Maximous DW, Elsayed MI, Mikhail NN. Surgical treatment for locally advanced lower third rectal cancer after neoadjuvent chemoradiation with capecitabine: prospective phase II trial. World journal of surgical oncology. Jun 92009

3. Phạm Cẩm Phương. Đánh giá hiệu quả của xạ trị kết hợp capecitabine trước mổ trong ung thư trực tràng thấp tiến triển tai chô. Luân án Tiến sỹ. Trường Đại học Y Hà Nội; 2013

4. Pham Khánh Toàn. Nhận xét môt số đăc điểm lâm sàng, cân lâm sàng và kết quả xạ trị gia tốc tăng phân liều trước mổ ung thư trực tràng giai đoan T3-T4. Luân văn Thac sỹ y hoc. Trường Đai học Y Hà Nội; 2013

5. HammadTeama A, AbdelsamieAlarabawy $R$,
AbdelhadyMohamed $\mathrm{H}$, HanyEissa $\mathrm{H}$. The Egyptian Journal of Radiology and Nuclear Medicine. ScienceDirect. 2015;46(4):833- 846.

6. Sun YS, Li XT, Zhang XY, Tang L, Cui Y, Zhang $\mathbf{X P}$. [Preoperative staging of rectal carcinoma with high-resolution MRI: correlation with histopathologic findings]. Zhonghua wai ke za zhi [Chinese journal of surgery]. Mar 2012; 50(3):207-10.

7. Võ Văn Xuân, Nguyến Đại Bình, Ngô Vĩ Dung. Nghiên cứu áp dung kỹ thuất xa tri gia tốc tăng phấn liều tiên phẩu kểt hợp với phẩu thuật ung thư trực tràng. Tap chí Ung thư hoc Viêt Nam. 2012; 2:57-66.

8. Kim JC, Kim TW, Kim JḦ, et al. Preoperative concurrent radiotherapy with capecitabine before total mesorectal excision in locally advanced rectal cancer. International journal of radiation oncology, biology, physics. Oct 1 2005;63(2):346-53.

9. Chamlou R, Parc Y, Simon T, et al. Long-term results of intersphincteric resection for low rectal cancer. Annals of surgery. Dec 2007;246(6):91621; discussion 921-2.

\section{ĐÁNH GIÁ KẾT QUẢ PHẪU THUÂT VÁ NHĨ TRONG ĐIỀU TRI VIÊM TAI GIŨ̃ A MAN TÍNH KHÔNG NGUY HIỂM Ở TRẺ EM DƯớI 16 TUỔI}

\section{TÓM TẮT}

Mục tiêu: Đánh giá kết quả phẫu thuật vá nhĩ trong điều trị viêm tai giữa mạn tính không nguy hiểm ở trẻ em đồ tuổi dưới 16. Phương pháp nghiên cứu: mô tả cắt ngang có can thiệp. Địa điểm nghiên cứu: Bênh viên Đai hoc Y Hà Nôi và Bênh viên Tai Mũi Họng Trung ương. Bệnh nhân: 29 bệnh nhân viêm tai giữa man tính không nguy hiểm trong đô tuổi từ 816 tuổi được phẫu thuật vá nhĩ từ 6/2020- 8/2021. Kết quả: Tỷ lệ đóng kín lỗ thủng màng nhĩ sau phẫu thuâtt trên 6 tháng chiếm $86,2 \%$, PTAac trước phẫu thuẩt là 28,06 dB sau phẫu thuât 20,86 dB, ABG trước phẫu thuật là 24,13 dB sau phấu thuật 14,66 dB. Kết luân: Tỷ lệ vá nhĩ thành công trong điều trị viêm tai giữa mạn tính không nguy hiểm ở trẻ em độ tuổi 8- 16 là tương đương với người lớn.

Tư khóa: Phẫu thuâtt vá nhĩ trẻ em, phẫu thuật tạo hình tai giữa typ 1 ở trẻ em

\section{SUMMARY \\ OUTCOME ASESSMENT OF TYMPANOPLASTY SURGERY MEASURE FOR CHRONIC OTITIS MEDIA TREATMENT WITHOUT CHOLESTEATOMA}

*Bệnh viện trẻ em Hải phòng

**Trướng Đai hoc Y Hà Nôi

Chịu trách nhiệm chính: Bùi Duy Vũ

Email: anhvu1981hy@gmail.com

Ngày nhận bài: 29.7.2021

Ngày phản biên khoa hoc: 29.9.2021

Ngày duyệt bài: 5.10 .2021
Bùi Duy Vũ *, Cao Minh Thành**

IN THE PEDIATRIC UNDER 16 YEARS

Objective: the purpose of this study was assess the value of tympanoplasty surgery measure for chronic otitia media treatment without cholesteatoma in the pediatric under 16 years. Methods: crosssectional descriptive study. Place of study: In National ENT Hospital and Ha Noi Hospital university of medicine.Patients: twenty nine patients were operated closure of tympntic membrane perforation aged between 8 and 16 years from June 2020 to August 2021. Results: the prevalent of closure of tympanic membrane perforation occupied $86,2 \%$ after 6 months surgery. Preoperative PTAac was $28.06 \mathrm{~dB}$ compared to 20,86 dB Postopertive. Preoperative ABG was $24,13 \mathrm{~dB}$ compared to $14,66 \mathrm{~dB}$ Postopertive. Conclusion: tympanoplasty success rates for treatment of no danger otitis media in pediatric population aged between 8 and 16 years were similar to adults.

Keywords:Tympanoplasty in pediatric patients,Typ 1 tympanoplasty in pediatric pateints.

\section{I. ĐĂTT VẤN ĐỀ}

Viêm tai giữa mạn tính (VTGMT) là bệnh thường gặp ở Việt Nam và trên thế giới, nhất là ở trẻ em. Phẫu thuật vá nhĩ (tạo hình tai giữa typ I) là phương pháp cơ bản để điêuu trị VTGMT không nguy hiểm. Phẫu thuật tạo hình tai giữa (THTG) được Wüllstein và Zöller phổ biến vào giữa những năm 19501,2,3. Các lý do được đưa ra làm kết quả phẫu thuật vá nhĩ của trẻ em kém 